\title{
Chronic Morphine Modulates the Contents of the Endocannabinoid, 2-Arachidonoyl Glycerol, in Rat Brain
}

\author{
Daniela Viganò', Maria Grazia Cascio², Tiziana Rubino', Filomena Fezza², Angelo Vaccani', Vincenzo Di \\ Marzo ${ }^{2}$ and Daniela Parolaro*, I \\ 'DBSF, Pharmacology Unit, University of Insubria, Busto Arsizio (VA), Italy; ${ }^{2}$ Endocannabinoid Research Group, Istituto di Chimica Biomolecolare, \\ CNR, Pozzuoli (NA), Italy
}

\begin{abstract}
Opioids and cannabinoids are among the most widely consumed drugs of abuse in humans and the phenomena of cross-tolerance or mutual potentiation have been demonstrated between the two drugs. Several authors have suggested that both drugs share common links in their molecular mechanisms of action, although this has been a matter of controversy. Furthermore, no data exist on the possible adaptive changes in the contents of arachidonoylethanolamide (anandamide, AEA) and 2-arachidonoylglycerol (2-AG), the two major endogenous ligands for cannabinoid receptors, in morphine-tolerant rats. In the present work, we investigated the alterations in cannabinoid receptor functionality and endocannabinoid levels in rats chronically treated with morphine ( 5 mg/kg, s.c., twice a day for 5 days). Autoradiographic-binding studies using $\left[{ }^{3} \mathrm{H}\right] \mathrm{CP}-55940$ revealed a slight but significant reduction in cannabinoid receptor level in the cerebellum and hippocampus of morphine-tolerant rats, while CP-55 940-stimulated $\left[{ }^{35} \mathrm{~S}\right] \mathrm{GTP} \gamma \mathrm{S}$ binding showed a strong decrease (40\%) in receptor/G protein coupling in the limbic area of these animals. Moreover, in the same brain regions we measured, by isotopedilution gas chromatography/mass spectrometry, the contents of AEA and 2-AG. Chronic morphine exposure produced a strong reduction in 2-AG contents without changes in AEA levels in several brain regions (ie striatum, cortex, hippocampus, limbic area, and hypothalamus). These findings clearly demonstrate that prolonged activation of opioid receptors could alter the cannabinoid system, in terms of both receptor functionality and endocannabinoid levels, and suggest the involvement of this system, alone or in combination with other mediators, in the phenomenon of morphine tolerance.
\end{abstract}

Neuropsychopharmacology (2003) 28, I | 60-I | 67, advance online publication, 12 March 2003; doi: I0. I038/sj.npp. I 300 I I7

Keywords: chronic morphine; cannabinoid receptor; endocannabinoid levels

\section{INTRODUCTION}

Opiates and cannabinoids are two classes of psychoactive drugs that share a similar pharmacological profile: both induce analgesia, hypothermia, sedation, hypotension, inhibition of intestinal motility and locomotor activity, changes in mood, and depression of the immune function (Manzanares et al, 1999; Massi et al, 2001). At the cellular level they activate different receptors, which are both coupled to Gi/Go GTP-binding proteins and inhibit adenylyl cyclase activity, block voltage-dependent calcium channels, and activate potassium channels. Receptors for these drugs are co-localized in the same neurons in various brain areas (caudate putamen, hippocampus, and substantia nigra) and might also compete for the same pool of Gi proteins (Childers et al, 1992).

*Correspondence: D Parolaro, DBSF, Pharmacology Unit, University of Insubria, via A. da Giussano 10, 21052 Busto Arsizio (VA), Italy, Tel: +390331 339417, Fax: +390331339459,

E-mail: daniela.parolaro@uninsubria.it

Received II June 2002; revised 5 November 2002; accepted 15 November 2002

Online publication: 22 November 2002 at http://www.acnp.org/ citations/Npp I 12202433
It is now well-established that opiates and cannabinoids exhibit cross-tolerance and/or mutual potentiation for antinociception after chronic treatment (Thorat and Bhargava, 1994; Rowen et al, 1998; Cichewicz et al, 2001; Rubino et al, 1997). The nature of such interactions is still unclear: some studies have reported that chronic exposure to opiates results in alterations of cannabinoid receptor density and/or signal transduction (Rubino et al, 1997; Romero et al, 1998; Shapira et al, 1998; Gonzalez et al, 2002). On the other hand, in mice where the 'central' cannabinoid $\mathrm{CB}_{1}$ receptor was genetically deleted $\left(\mathrm{CB}_{1}\right.$ knockout mice), the acute effects of opiates were unaffected (Ledent et al, 1999), whereas the reinforcing properties of morphine and the severity of the withdrawal syndrome were strongly reduced (Ledent $e t$ al, 1999). Moreover the acute administration of SR141716, a selective central cannabinoid $\mathrm{CB}_{1}$ receptor antagonist, blocked heroin self-administration in rats as well as morphine-induced place preference and morphine selfadministration in mice (Navarro et al, 2001).

Recently, some authors have suggested that the functional interaction between opioids and cannabinoids could be ascribed to alterations of the output of their endogenous tone. In fact, the induction of the synthesis and/or release of endogenous opioid peptides after exposure to cannabinoids 
have been demonstrated (Pugh et al, 1996; Welch and Eads, 1999, Valverde et al, 2001). By contrast, no data are available on possible alterations of the endocannabinoid system in the CNS after prolonged exposure to morphine. Therefore, we undertook the present study with the aim of investigating, in several brain regions of rats chronically treated with morphine, possible changes of the levels of: (1) cannabinoid receptor-binding sites and G-protein-coupled activity, and (2) anandamide (AEA) and 2-arachidonoylglycerol (2-AG), the two major endogenous ligands of cannabinoid receptors (Di Marzo et al, 1998).

\section{METHODS}

\section{Animals and Treatment}

Male Sprague-Dawley rats (Charles River, Calco, Italy) weighing 125-150 $\mathrm{g}$ at the beginning of the experiment were used. The animals were housed three per cage in standard conditions. After about 1 week of habituation, the rats received morphine hydrocloride (SALARS, Como, Italy) twice a day (between 9:00 and 10:00 am and 5:00 and $6: 00 \mathrm{pm}$ ) for 4.5 days at a dose of $5 \mathrm{mg} / \mathrm{kg}$ s.c. Control rats received the same treatment with saline. On days 1,3 , and 5 the analgesic effect of morphine was evaluated by the tail flick test to monitor the development of tolerance. Pain thresholds were evaluated $15,30,60$, and 120 min after the morning dose. A maximum cutoff time of $15 \mathrm{~s}$ was used and the rat was removed from the apparatus if it failed to respond within this interval. The results were expressed as total area under the time-response curve (AUC) over the $120 \mathrm{~min}$. This chronic regimen of morphine administration induced a clear development of tolerance as previously demonstrated (Massi et al, 2001). In the acute condition rats received a single morphine injection ( $5 \mathrm{mg} / \mathrm{kg}$, s.c.) or saline.

\section{Autoradiographic-Binding Studies}

For autoradiographic-binding studies rats were killed by decapitation $2 \mathrm{~h}$ after the last morphine or saline injection. This interval of time after the last treatment is needed in order to avoid any interference of the residual drug injected in vivo. The brains were rapidly removed and frozen into liquid nitrogen. They were stored at $-80^{\circ} \mathrm{C}$ until processing. Sagittal sections of $20 \mu \mathrm{m}$ were cut on a cryostat and thawmounted onto gelatin-coated slides and stored at $-80^{\circ} \mathrm{C}$ until use. Adjacent sections from the same brains were used for the two assays.

$\left[{ }^{3} \mathrm{H}\right] \mathrm{CP}-55940$ receptor autoradiography. The slides were brought rapidly to room temperature, then incubated for $2.5 \mathrm{~h}$ at $37^{\circ} \mathrm{C}$ with $10 \mathrm{nM}\left[{ }^{3} \mathrm{H}\right] \mathrm{CP}-55940$ (Perkin-Elmer Life Science, Milan, Italy) in binding buffer $(50 \mathrm{mM}$ Tris- $\mathrm{HCl}$, $\mathrm{pH} 7.4,5 \%$ BSA). Adjacent cerebral sections were coincubated in parallel with $10 \mu \mathrm{M}$ CP-55940 to assess nonspecific binding. Sections were washed for $1 \mathrm{~h}$ at $0^{\circ} \mathrm{C}$ in $50 \mathrm{mM}$ Tris- $\mathrm{HCl} \mathrm{pH} \mathrm{7.4,1 \%} \mathrm{BSA} \mathrm{buffer} \mathrm{and} \mathrm{left} \mathrm{in} \mathrm{the}$ same conditions for $3 \mathrm{~h}$. Sections were then dipped in

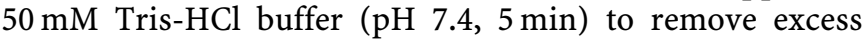
BSA, dipped briefly in distilled water $(1 \mathrm{~min})$, and dried under a cool air stream. Autoradiograms were generated by exposing the dried sections for 7 days to tritium-sensitive film, Hyperfilm- ${ }^{3} \mathrm{H}$ (Amersham Pharmacia Biotech, Milan, Italy).

Agonist-stimulated $\left[{ }^{35} S\right] G T P \gamma S$ autoradiography. Cannabinoid-stimulated $\left[{ }^{35} \mathrm{~S}\right] \mathrm{GTP} \gamma \mathrm{S}$ binding was determined as described previously by Sim et al (1996) with slight modifications. Briefly, slides were incubated in assay buffer (50 mM Tris- $\mathrm{HCl}, 3 \mathrm{mM} \mathrm{MgCl}_{2}, 0.2 \mathrm{mM} \mathrm{EGTA,} 100 \mathrm{mM}$ $\mathrm{NaCl}, 0.1 \% \mathrm{BSA}$, adenosine deaminase $10 \mathrm{mU} / \mathrm{ml}, \mathrm{pH} 7.4$ ) at $25^{\circ} \mathrm{C}$ for $10 \mathrm{~min}$ and then in $3 \mathrm{mM}$ GDP in assay buffer at $25^{\circ} \mathrm{C}$ for $15 \mathrm{~min}$. Slides were then transferred into assay buffer containing $3 \mathrm{mM}$ GDP and $0.04 \mathrm{nM}\left[{ }^{35} \mathrm{~S}\right] \mathrm{GTP} \gamma \mathrm{S}$ (Perkin-Elmer Life Science, Milan, Italy) with (stimulated) or without (basal) $5 \mu \mathrm{M} \mathrm{CP}-55,940$ and incubated at $25^{\circ} \mathrm{C}$ for $2 \mathrm{~h}$. Slides were rinsed twice in cold $50 \mathrm{mM}$ Tris buffer and once in deionized water, dried, and exposed to $\beta_{\max }$ film (Amersham Pharmacia Biotech, Milan, Italy) for $48 \mathrm{~h}$.

Image analysis. The image intensity of the autoradiographic film was assessed by measuring the gray levels with an image analysis system consisting of a video camera (Hamamatsu, Photonics K.K., Tokyo, Japan) connected to an Apple MacIntosh II personal computer. The public domain Image 1.47 software was used (National Institute of Health, Bethesda, MD). Each cerebral area was traced with the mouse cursor control and the light transmittance was determined as the gray level. The gray level of densitometric measurements calculated after subtraction of the film background density was established within the linear range, determined by using tritium standards $\left({ }^{3} \mathrm{H}\right.$ Microscales, Amersham Pharmacia Biotech, Milan, Italy) for receptorbinding studies, and $\left[{ }^{35} \mathrm{~S}\right]$-labelled standards prepared in laboratory for $\left[{ }^{35} \mathrm{~S}\right] \mathrm{GTP} \gamma \mathrm{S}$-binding studies.

\section{Measurement of Endocannabinoid Contents}

Dissection procedure. Rats were killed $2 \mathrm{~h}$ after the last morphine or saline injection, and the brains were quickly and carefully removed; the following areas, striatum, cortex, hippocampus, limbic area (that contains nucleus accumbens, septum nuclei, and parts of the anterior amygdaloid nuclei) hypothalamus, mesencephalon, and cerebellum were rapidly dissected on ice using the Paxinos and Watson atlas (1986) for morphological orientation, and immediately frozen at $-80^{\circ}$ to avoid the post-mortem rise in the concentrations of long-chain $N$-acylethanolamines. This starts approximately $30 \mathrm{~min}$ after sacrifice, as reported by Schmid et al (1995).

Procedure of extraction. Each brain region was extracted when still frozen. The tissue was homogenized in $5 \mathrm{vol}$ of chloroform/methanol/Tris- $\mathrm{HCl} 50 \mathrm{mM}(2: 1: 1)$ containing $1 \mathrm{nmol}$ of $\mathrm{d}_{8}$-AEA and $\mathrm{d}_{8}-2-\mathrm{AG}$. Deuterated standards were synthesized from $d_{8}$ arachidonic acid and ethanolamine or glycerol as described, respectively, in Devane et al (1992) and Bisogno et al (1997). Homogenates were centrifuged at $13000 \mathrm{~g}$ for $16 \mathrm{~min}\left(4^{\circ} \mathrm{C}\right)$, the aqueous phase plus debris were collected and extracted again twice with $1 \mathrm{vol}$ of chloroform. The organic phases from the three extractions were pooled and the organic solvents evaporated in a 
rotating evaporator. Lyophilized samples were then stored frozen at $-80^{\circ} \mathrm{C}$ under nitrogen atmosphere until analyzed.

Analysis of endocannabinoid contents by GC/MS. Lyophilized extracts were resuspended in chloroform/methanol 99: 1 by vol. The solutions were then purified by open bed chromatography on silica as described in Fontana et al (1995). Fractions eluted with chloroform/methanol 9:1 by vol. (containing AEA and 2-AG) were collected and the excess solvent evaporated with a rotating evaporator. The former fractions were further fractionated by normal phase high-pressure liquid chromatography (NP-HPLC) carried out using a semipreparative silica column (Spherisorb S5W, Phase Sep, Queensferry, CLWYD, UK) eluted with a $40 \mathrm{~min}$ linear gradient from $9: 1$ to $8: 2$ (by vol) of $n$-hexane/2propanol (flow rate $=2 \mathrm{ml} / \mathrm{min}$ ). These elution conditions allow the separation of 1(3)- and 2-acyl-glycerols (retention time of 18 and $20 \mathrm{~min}$, respectively) from $\mathrm{N}$-acylethanolamines (retention time $=26-27 \mathrm{~min}$ ). NP-HPLC fractions from 17 to $22 \mathrm{~min}$ and from 24 to $28 \mathrm{~min}$ were pooled, the solvent evaporated in a speed-vac, and the components derivatized with $20 \mu \mathrm{l} N$-methyl- $N$-trimethylsilyl-trifluoroacetamide $+1 \%$ trimethylchlorosylane for $2 \mathrm{~h}$ at room temperature and analyzed by gas chromatography/mass spectrometry (GC-MS) carried out under conditions described previously (Bisogno et al, 1997) and allowing the separations of monoacylglycerols or $\mathrm{N}$-acylethanolamines with different fatty acid chains. MS detection was carried out in the selected ion monitoring mode using $\mathrm{m} / z$ values of 427 and 419 (molecular ions for deuterated and undeuterated AEA), 412 and 404 (loss of 15 mass units from deuterated and undeuterated AEA), 530 and 522 (molecular ions for deuterated and undeuterated 2-AG), and 515 and 507 (loss of 15 mass units from deuterated and undeuterated 2-AG). The area ratios between signals of deuterated and undeuterated AEA varied linearly with varying amounts of undeuterated AEA ( $20 \mathrm{pmol}-20 \mathrm{nmol})$. The same applied to the area ratios between signals of deuterated and undeuterated 2-AG in the $100 \mathrm{pmol}-20 \mathrm{nmol}$ interval. AEA and 2-AG levels in unknown samples were therefore calculated on the basis of their area ratios with the internal deuterated standard signal areas. Two GC-MS peaks for both deuterated and undeuterated mono-arachidonoylglycerol were found, corresponding to $2-A G$ and $1(3)-A G$, in agreement with the previous observation that $2-A G$ undergoes isomerization during the purification procedure (Stella et al, 1997). Therefore, the amounts of 2-AG were calculated by adding the amounts of the two isomers. The amounts of endocannabinoids are expressed as pmol or nmol per gram of wet tissue extracted. Further details on the GC/MS technique, including the detection and quantification limits, have been published (De Petrocellis et al, 1999).

\section{Statistical analysis}

The data presented in the figures are means \pm SEM of at least five animals. Statistical analysis of the data was carried out by using the Student's $t$-test and the one-way analysis of variance (ANOVA) followed by Tukey's and Bonferroni's test performed by Prism (GraphPad Software, Inc.).

\section{RESULTS}

\section{Behavioral Studies}

The acute injection of morphine $(5 \mathrm{mg} / \mathrm{kg}$, s.c.) in rats elicited a significant degree of analgesia and as expected, rats chronically treated with morphine $(5 \mathrm{mg} / \mathrm{kg}$, s.c., twice a day for 4.5 days) developed tolerance to its analgesic effect (Figure 1).

\section{Autoradiographic-Binding Studies}

At $2 \mathrm{~h}$ after the last morphine injection, rats were killed, and the brain was quickly removed for autoradiographic studies of $\left[{ }^{3} \mathrm{H}\right] \mathrm{CP}-55940$ binding to $\mathrm{CB}_{1}$ receptors and agonist-stimulated $\left[{ }^{35} \mathrm{~S}\right] \mathrm{GTP} \gamma \mathrm{S}$ binding. First, we checked the effect of acute morphine on these parameters, and alterations were found neither in $C_{1}$ receptor binding nor in CP-55940-stimulated $\left[{ }^{35} \mathrm{~S}\right] \mathrm{GTP} \gamma \mathrm{S}$ binding (data not shown). Figure 2 shows the results of densitometric analysis of rat brain sagittal sections in animals given morphine or saline chronically. Five days exposure of morphine induced a slight (15\%) but significant downregulation of cannabinoid receptor in the hippocampus and cerebellum, without any changes in the other regions. Representative autoradiograms of rat brain sagittal sections showing the effect of chronic morphine administration on cannabinoid receptor binding are presented in Figure 2.

Since the cannabinoid receptor is linked to the $G$ protein transduction system, the second step in our work was to check for any alteration in receptor/G protein coupling following chronic morphine administration. We assayed cannabinoid-stimulated $\left[{ }^{35} \mathrm{~S}\right] \mathrm{GTP} \gamma \mathrm{S}$ binding, with $\mathrm{CP}$ 55940 as the agonist. Basal $\left[{ }^{35} \mathrm{~S}\right] \mathrm{GTP} \gamma \mathrm{S}$ binding was not affected by chronic morphine in any of the considered cerebral areas (data not shown). By contrast, prolonged exposure to morphine significantly decreased the net binding value only in the limbic area $(40 \%)$, whereas no significant differences were found between morphinetreated and control rats in the other regions (Figure 3 ).

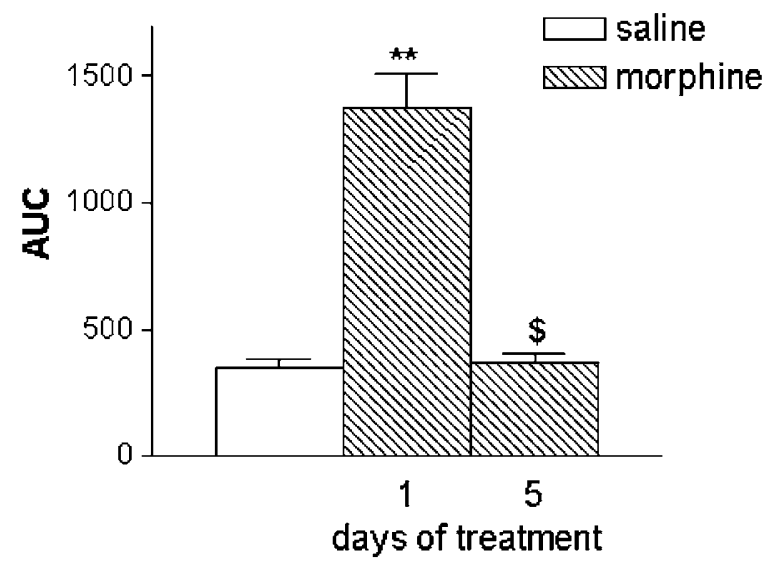

Figure I Effect of morphine ( $5 \mathrm{mg} / \mathrm{kg}$, s.c., twice a day for 4.5 days) on analgesia expressed as area under the analgesic curve (AUC). The data are the means \pm SEM of at least five animals. ${ }^{*} p<0.0$ l by one-way ANOVA followed by Tukey's test vs saline; $\$ p<0.05$ by one-way ANOVA followed by Tukey's test vs morphine I day. 


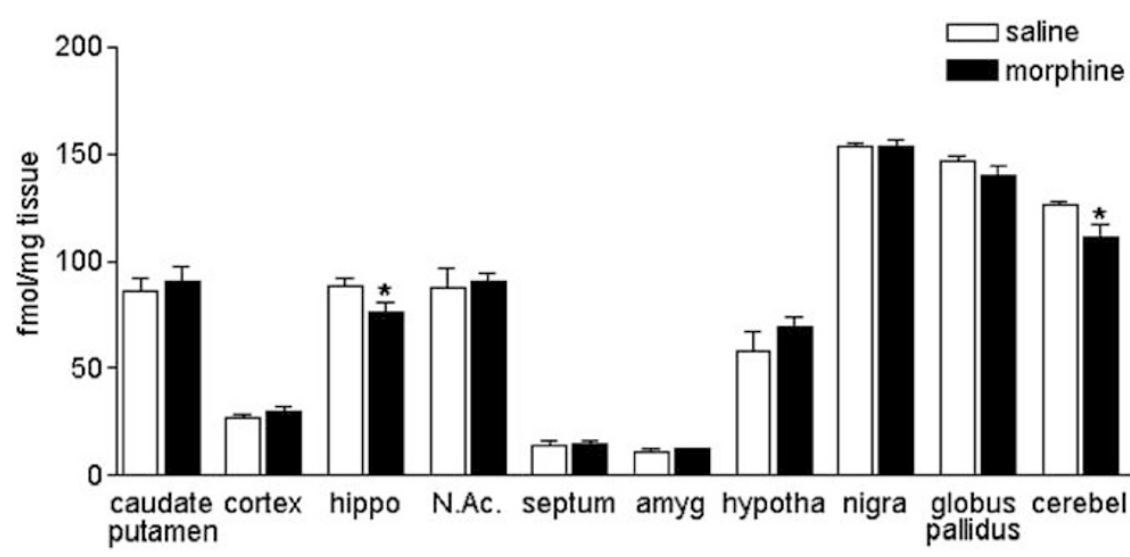

SALINE

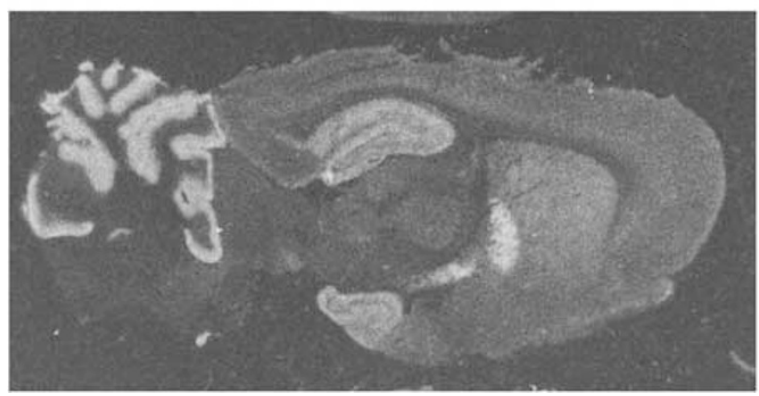

MORPHINE

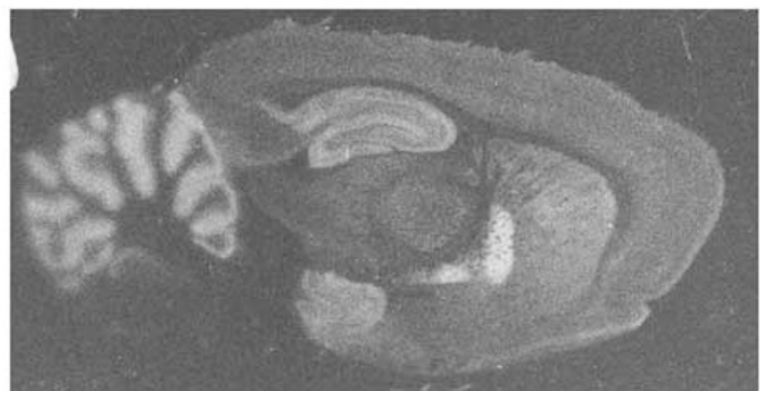

Figure 2 Effect of morphine chronic treatment on $\mathrm{CB}_{\text {| }}$ receptor binding in different rat brain areas. Gray levels obtained with densitometric analysis were transformed into $\mathrm{fmol} / \mathrm{mg}$ tissue using $\left[{ }^{3} \mathrm{H}\right]$ standards. Bars indicate the means $\pm \mathrm{SEM}$ of at least five animals (three sections/animal). * $p<0.05$ by Student's $t$ test vs saline. The bottom panel shows autoradiograms of representative sagittal sections of the brain of saline and morphine rats. hippo: hippocampus; N. Ac.: nucleus accumbens; amyg: anterior amygdala; hypothal: hypothalamus; nigra: substantia nigra; cerebel: cerebellum.

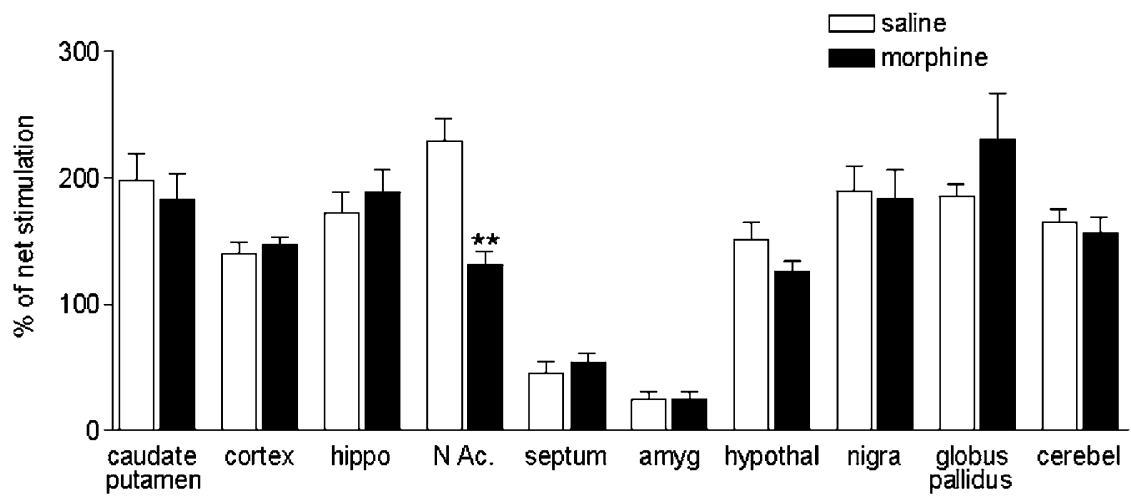

Figure 3 Effect of morphine chronic treatment on net cannabinoid-stimulated $\left.{ }^{35} \mathrm{~S}\right] \mathrm{GTP} \gamma \mathrm{S}$ binding in different brain regions, determined by subtracting basal $\left[{ }^{35}\right.$ S]GTP $\gamma S$ binding. Bars indicate the means \pm S.E.M. of at least five animals (six sections/animal). *** $p<0.005$ by Student's $t$-test vs saline. hippo: hippocampus; N. Ac.: nucleus accumbens; amyg: anterior amygdala; hypothal: hypothalamus; nigra: substantia nigra; cerebel: cerebellum.

\section{Endocannabinoid Contents}

The contents of both endocannabinoids, AEA and 2-AG, measured in seven brain regions of control-injected rats, were mostly similar to those previously reported by other authors (Di Marzo et al, 2000a; Bisogno et al, 1999; Felder et $a l, 1996)$ in naive and control animals, allowing for the large standard deviations with which these compounds are usually quantified by the GC/MS technique. In a pilot study, acute morphine treatment did not induce any changes of either AEA or 2-AG levels in rat whole brain (data not shown). Therefore, we focused on chronic morphine treatment, which instead produced a dramatic decrease in 2-AG contents in most of the brain regions analyzed, that is, striatum (69\%), cortex (62\%), hippocampus (42\%), limbic area (42\%), and hypothalamus (35\%), with no significant alterations in the mesencephalon and cerebellum (Figure 4). On the contrary, no statistically significant alterations were found in any of the cerebral regions in the levels of AEA after 5 days of morphine 
2-AG

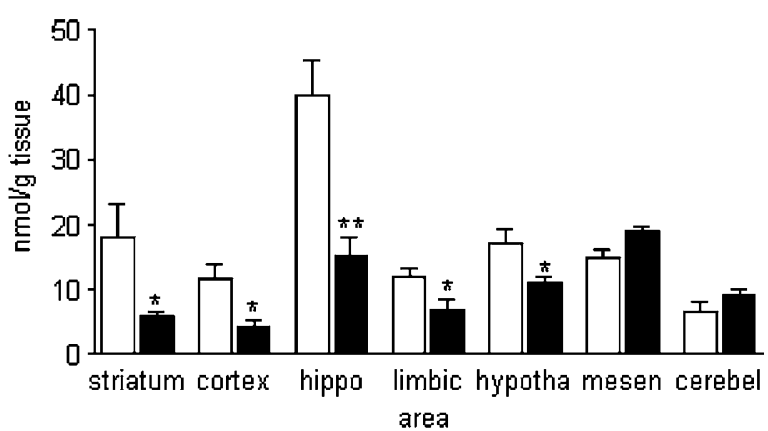

AEA

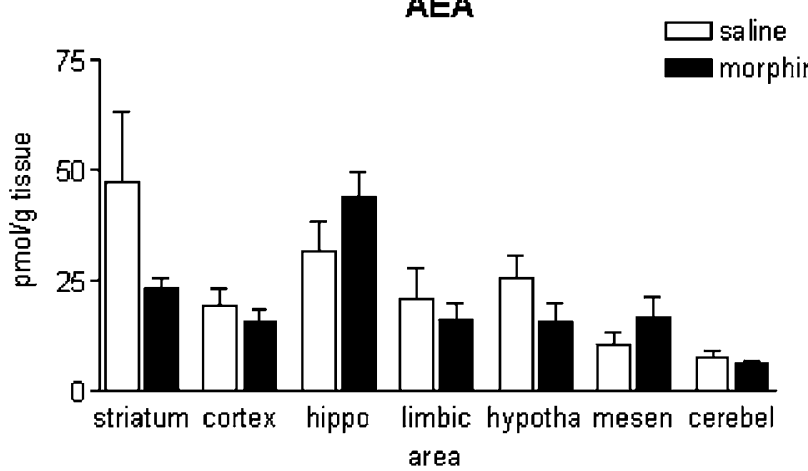

Figure 4 (a) Effect of morphine chronic treatment on 2-AG and anandamide (AEA) contents measured in different rat brain regions. Values are means \pm SEM of four determinations/each corresponding to a different pool of animals. * $p<0.05$; ** $p<0.005$ by one-way ANOVA followed by Bonferroni's test vs saline. hippo: hippocampus; hypothal: hypothalamus; nigra: substantia nigra; cerebel: cerebellum.

treatment, although a trend for a decrease was observed in the striatum (Figure 3). As a control, we measured the amounts of the anandamide congener, $N$-palmitoylethanolamine (PEA), a substance with cannabimimetic actions and little, if any, binding affinity to cannabinoid receptors. We found no differences in its levels between control and treated animals in any of the brain regions under study (data not shown).

\section{DISCUSSION}

This study provides new insights into the molecular mechanisms of the crosstalk between opiates and cannabinoids. In morphine-tolerant rats we observed, limited to the hippocampus and cerebellum, a slight but significant decrease in $\mathrm{CB}_{1}$ receptor binding, which was not accompanied by a corresponding decrease in cannabinoid receptor-induced signal transduction. More importantly, a strong decrease in cannabinoid-induced $\left[{ }^{35} \mathrm{~S}\right] \mathrm{GTP} \gamma \mathrm{S}$ binding, but not in $\mathrm{CB}_{1}$ receptor binding, was observed in the limbic area, a region involved in the rewarding and addictive properties of morphine and other substances of abuse. None of these changes was observed in the brain of rats after acute administration of morphine. The region specificity of the changes observed could be related to the high density of $\mathrm{CB}_{1}$ receptors in these areas, and might correlate with the important functional roles in cognition (hippocampus), control of motor behavior (cerebellum), and reward processes (limbic area), of these regions. Previous studies demonstrated that chronic morphine exposure induces divergent and region-dependent effects on $\mathrm{CB}_{1}$ receptor expression, binding and signal transduction. In fact, some authors reported no significant changes in $\mathrm{CB}_{1}$ receptors in mice chronically treated with morphine (Romero et al, 1998), while other recent studies carried out in morphine-tolerant rats reported both a decrease (in the cerebellum and hippocampus) and an increase (in the caudate putamen and most of the limbic structures) in different brain regions (Gonzalez et al, 2002), or an increase in the caudate putamen only (Rubino et al, 1997) of the density of cannabinoid $\mathrm{CB}_{1}$ receptor protein and/or mRNA. These somehow discrepant data are likely because of the different species, strains, and protocols used to induce tolerance. The protocol used in the present study was milder than that used in previous investigations, but it was nevertheless able to induce tolerance to the analgesic effect of morphine.

Our study presents for the first time data regarding alterations in the contents of endocannabinoids in the brain of morphine-tolerant rats. Chronic treatment with morphine produced a widespread decrease in 2-AG contents without significant changes in AEA levels, therefore suggesting that this treatment influences in a different way the regulatory mechanisms controlling AEA and 2-AG homeostasis in the brain. Again, no change was observed after acute administration of morphine. Thus, the endocannabinoid system, besides being involved in the development of tolerance to $\Delta^{9}$-THC (Di Marzo et al, 2000a), might play an important role also in opiate tolerance (see below). However, it must be emphasized that chronic exposure to cannabinoids and opioids influences endocannabinoid levels in a different way, in terms of both the brain region and the type of endocannabinoid affected. In fact, according to Di Marzo et al (2000a), chronic $\Delta^{9}$-THC induced an increase in AEA contents only in the limbic forebrain, without affecting 2-AG levels, whereas a decrease of both endocannabinoids was found in the striatum. By contrast, in the present study, chronic morphine affected 2AG levels in five out of the seven regions examined without significantly altering AEA levels, although, like with chronic THC treatment (Di Marzo et al, 2000a), a decrease of 2-AG and a trend for a decrease of AEA was observed in the caudate putamen. Interestingly, the regions where chronic morphine decreased 2-AG levels to the highest extent were also those with the highest density of $\mathrm{CB}_{1}$ receptors, thus potentially leading to a strong impact on endocannabinoid signalling in these regions. In particular:

(1) In the caudate putamen, we observed a significant decrease in the contents of 2-AG without any alterations in $\mathrm{CB}_{1}$ receptor functionality, which might result in a decreased endocannabinoid transmission. This event, as discussed by Di Marzo et al (2000a) for THC-tolerant rats, could explain in part the loss of motor inhibition by morphine observed in rats made 
tolerant to this drug. In fact, endocannabinoids in the striatum are thought to depress motor activity, probably through both inhibition of dopamine neurotransmission and enhancement of GABAmediated effects (Glass et al, 1997; Di Marzo et al, 1998).

(2) In the cortex the picture was similar to that observed in the caudate putamen, that is, no changes in the receptor functionality with decreased 2-AG levels, thus again potentially resulting in a decreased endocannabinoid tone. In this area, cannabinoids inhibit the release of glutamate, which, at the level of cortico-striatal synapses, causes an impairment of motor coordination. Thus, the observed decrease in 2-AG amounts could at least in part account for the loss of morphine effect on motor coordination in morphine-tolerant rats (Auclair et al, 2000).

(3) In the hippocampus, we found a decrease of both 2-AG contents and receptor binding. We found, however, no changes in receptor/G protein coupling, suggesting the presence of $\mathrm{CB}_{1}$ receptors with increased functionality. This might represent an adaptive process induced in hippocampal neurons to counteract the reduced endocannabinoid levels. In fact, previous data obtained using $\mathrm{CB}_{1}$ knockout mice showed that: (1) the endocannabinoid system is tonically active in the hippocampus with the function of controlling acetylcholine and glutamate signalling, long-term potentiation, and memory (Bohme et al, 2000; Martin et al, 2002); (2) the levels/activity of $\mathrm{CB}_{1}$ receptors and their ligands are tightly and mutually regulated in this region (Di Marzo et al, 2000b).

(4) In the hypothalamus, we observed a reduction of 2-AG amounts again with no changes in receptor functionality. As shown by studies using $\mathrm{CB}_{1}$ knockout mice, an endocannabinoid tone in this brain area modulates the hypothalamic-pituitary axis as well as body temperature, appetite, and food intake (Di Marzo et al, 2001; Wenger et al, 2001). The decreased endocannabinoid transmission observed in this area could thus account in part for the reduced food intake observed in morphine chronically exposed rats, and for the development, in these animals, of tolerance to the hypothermic effect normally induced by acute morphine.

(5) In the limbic area, the reduction in cannabinoidstimulated $G$ protein activity was restricted to the nucleus accumbens, while we found a decreased 2-AG content analyzing the whole limbic area (nucleus accumbens, septum, and part of anterior amygdaloid nuclei), thus we cannot link the alteration in endocannabinoid levels to a specific brain regions belonging to the limbic area. Nevertheless, our data represent the first example of the existence of an alteration in limbic forebrain endocannabinoid levels and nucleus accumbens CB1 receptor signalling during chronic morphine. The observed reduction in $2-\mathrm{AG}$ content in this heterogeneous region could play a role in the complex emotional and motivational state observed during chronic morphine exposure, being the septum and anterior amygdala notoriously linked to the inhibition of anxiety-like responses (Adamec and Young, 2000) and the nucleus accumbens a key region in the reward neural circuitry as well as in drug and food craving and in drug addiction.

(6) Finally, the widespread reduced levels of 2-AG found in the brain of morphine-tolerant rats could account for the enhanced susceptibility to neurodegenerative processes observed after chronic morphine exposure (Pearson et al, 1975/76; Coomb et al, 1985; London et al, 1989; Sala et al, 1994). In fact, recently it has been demonstrated that 2-AG exerts a neuroprotective action in rats after brain injury (Panikashvili et al, 2001), and the reduction in its amounts could in part underlie morphine-induced premature aging (Sala $e t$ al, 1994).

In conclusion, our results suggest that the widely described interactions between opiates and cannabinoids, as well as some of the behavioral features of animals tolerant to morphine, might be partly because of decreased endocannabinoid levels together with changes in cannabinoid receptor binding and receptor/G protein coupling; the possible functional significance of these changes being dependent on the brain region where they occur. Of the two endocannabinoids most widely studied to date, only the levels of the 2-AG were found here to be significantly decreased in brain regions with the highest density of cannabinoid $\mathrm{CB}_{1}$ receptors. There are several possible reasons for this different behavior between AEA and 2-AG, which are produced and inactivated by neurons and astrocytes through different biochemical pathways. For example, it is possible that chronic morphine impacts more on the phospholipase $\mathrm{C}$ enzymes responsible for the biosynthesis of some 2-AG precursors, rather than on the phospholipase $\mathrm{D}$, which catalyses AEA production (Di Marzo et al, 1998). Alternatively, it is possible that prolonged treatment with the drug upregulates only the monoacylglycerol lipase responsible for 2-AG hydrolysis, and not the fatty acid amide hydrolase catalysing anandamide hydrolysis. Importantly, chronic morphine has been previously reported to both enhance phospholipase $C$ activity in rat mesolimbic neurons (Wolf et al, 1999) and reduce the formation of phospholipase $C$ products in chick neurons (Mangoura and Dawson, 1991). Clearly, a full characterization of all the proteins that participate in the regulation of endocannabinoid levels must be awaited before addressing this issue in greater detail. At any rate, our finding of selective effects on 2-AG levels might explain in part the recent report that exogenous 2-AG attenuates some of the signs caused by morphine withdrawal in morphine-dependent rats (Yamaguchi et al, 2001).

\section{ACKNOWLEDGEMENTS}

This research was supported by the Italian Ministry of University and Research, and by the Center of Behavioral Pharmacology, University of Milan to DP, and partly funded by MURST 3933 and Fondi Strutturali to VDM. We thank Mr. O. De Luca for his technical assistance. 


\section{REFERENCES}

Adamec R, Young B (2000). Neuroplasticity in specific limbic system circuit may mediate specific kindling induced changes in animal affect-implications for understanding anxiety associated with epilepsy. Neurosci Biobehav Rev 24: 705-723.

Auclair N, Otani S, Soubrie P, Crepel F (2000). Cannabinoids modulate synaptic strength and plasticity at glutamatergic synapses of rat prefrontal cortex pyramidal neurons. J Neurophysiol 83: 3287-3293.

Bisogno T, Berrendero F, Ambrosino G, Cebeira M, Ramos AJ, Fernandez-Ruiz JJ et al (1999). Brain regional distribution of endocannabinoids: implications for their biosynthesis and biological function. Biochem Biophys Res Comm 256: 377-380.

Bisogno T, Sepe N, Melck D, Maurelli S, De Petrocellis L, Di Marzo V (1997). Biosynthesis, release and degradation of the novel endogenous cannabimimetic metabolite 2-arachidonoyl-glycerol in mouse neuroblastoma cells. Biochem J 322: 671-677.

Bohme GA, Laville M, Ledent C, Parmentier M, Imperato A (2000). Enhanced long-term potentiation in mice lacking cannabinoid CB1 receptors. Neuroscience 95: 5-7.

Childers SR, Fleming L, Konkoy C, Marckel D, Pacheco M, Sexton $\mathrm{T}$ et al (1992). Opioid and cannabinoid receptor inhibition of adenylyl cyclase in brain. Ann NY Acad Sci 654: 33-51.

Cichewicz DL, Haller VL, Welch SP (2001). Changes in opioid and cannabinoid receptor protein following short-term combination treatment with $\Delta^{9}$-tetrahydrocannabinol and morphine. $J$ Pharmacol Exp Ther 297: 121-127.

Coombs DW, Fratkin JD, Meier FA, Nierenberg DW, Saunders RL (1985). Neuropathologic lesions and CSF morphine concentrations during chronic continuous intraspinal morphine infusion. A clinical and post-mortem study. Pain 22: 337-351.

De Petrocellis L, Melck D, Bisogno T, Milone A, Di Marzo V (1999). Finding of endocannabinoid signalling system in Hydra, a very primitive organism: possible role in the feeding response. Neuroscience 92: 377-387.

Devane WA, Hanus L, Bruer A, Pertwee RG, Stevenson LA, Griffin $\mathrm{G}$ et al (1992). Isolation and structure of a brain constituent that binds to the cannabinoid receptor. Science 258: 1946-1949.

Di Marzo V, Berrendero F, Bisogno T, Gonzalez S, Cavaliere P, Romero J et al (2000a). Enhancement of anandamide formation in the limbic forebrain and reduction of endocannabinoid contents in the striatum of $\Delta^{9}$-tetrahydrocannabinol-tolerant rats. J Neurochem 74: 1627-1635.

Di Marzo V, Breivogel CS, Tao Q, Bridgen DT, Razdan RK, Zimmer $\mathrm{AM}$ et al (2000b). Levels, metabolism, and pharmacological activity of anandamide in $\mathrm{CB}(1)$ cannabinoid receptor knockout mice: evidence for non- $\mathrm{CB}(1)$, non- $\mathrm{CB}(2)$ receptor-mediated actions on anandamide in mouse brain. J Neurochem 75: 24342444.

Di Marzo V, Goparaju SK, Wang L, Liu J, Batkai S, Jarai Z et al (2001). Leptin-regulated endocannabinoids are involved in maintaining food intake. Nature 410: 763-765.

Di Marzo V, Melck D, Bisogno T, De Petrocellis L (1998). Endocannabinoids: endogenous cannabinoid receptor ligands with neuromodulatory action. Trends Neurosci 21: 521-528.

Felder CC, Nielsen A, Briley EM, Palkovits M, Priller J, Axelrod J et al (1996). Isolation and measurement of the endogenous cannabinoid receptor agonist, anandamide, in brain and peripheral tissues of human and rat. FEBS Lett 393: 231-235.

Fontana A, Di Marzo V, Cadas H, Piomelli D (1995). Analysis of anandamide, an endogenous cannabinoid substance, and other natural $\mathrm{N}$-acylethanolamines. Prostaglandins Leukot. Essent Fatty Acids 53: 301-308.

Glass M, Brotchie J, Maneuf YP (1997). Modulation of neurotransmitters by cannabinoids in the basal ganglia. Eur J Neurosci 2: $358-363$.
Gonzalez S, Fernandez-Ruiz JJ, Sparpaglione V, Parolaro D, Ramos JA (2002). Chronic exposure to morphine, cocaine or ethanol in rats produced different effects in brain cannabinoid $\mathrm{CB}_{1}$ receptor binding and mRNA levels. Drug Alcohol Depend 66: 77-84.

Ledent C, Valverde O, Cossu G, Petitet F, Aubert JF, Beslot F et al (1999). Unresponsiveness to cannabinoids and reduced addictive effects of opiates in CB1 receptor knockout mice. Science 283: 401-404.

London ED, Margolin RA, Wong DF, Links J, La France ND, Cascella NG et al (1989). Cerebral glucose utilization in human heroin addicts: case reports from a positron emission tomographic study. Res Commun Substances Abuse 10: 141-144.

Mangoura D, Dawson G (1991). Chronic opioid treatment attenuates carbachol-mediated polyphosphoinositide hydrolysis in chick embryo neuronal cultures. Brain Res 548: 273-278.

Manzanares J, Corchero J, Romero J, Fernandez-Ruiz JJ, Ramos A, Fuentes JA (1999). Pharmacological and biochemical interactions between opioids and cannabinoids. Trends Pharmacol Sci 20: 287-294.

Martin M, Ledent C, Parmentier M, Maldonado R, Valverde O (2002). Involvement of CB1 cannabinoid receptors in emotional behaviour. Psychopharmacology 159: 379-87.

Massi P, Vaccani A, Romorini S, Parolaro D (2001). Comparative characterization in the rat of the interaction between cannabinoids and opiates for their immunosuppressive and analgesic effects. J Neuroimmunol 117: 116-124.

Navarro M, Carrera MN, Fratta W, Valverde O, Cossu G, Fattore L et al (2001). Functional interaction between opioid and cannabinoid receptors in drug self-administration. J Neurosci 21: 5344-5350.

Panikashvili D, Simeonidou C, Ben-Shabat S, Hanus L, Breuer A, Mechoulam $\mathrm{R}$ et al (2001). An endogenous cannabinoid (2-AG) is neuroprotective after brain injury. Nature 413: 527-531.

Paxinos G, Watson C (1986). The Rat Brain in Stereotaxic Coordinates. Academic Press: London.

Pearson J, Baden MB, Richter RW (1975/76). Neuronal depletion in the globus pallidus of heroin addicts. Drug Alcohol Depend 1: 349-356.

Pugh G, Smith PB, Dombrowski DS, Welch SP (1996). The role of endogenous opioids in enhancing the antinociception produced by the combination of $\Delta^{9}$-tetrahydrocannabinol and morphine in the spinal cord. J Pharmacol Exp Ther 279: 608-616.

Romero J, Fernandez-Ruiz JJ, Vela G, Ruiz-Gayo M, Fuentes JA, Ramos JA (1998). Autoradiographic analysis of cannabinoid receptor binding and cannabinoid agonist-stimulated $\left[{ }^{35} \mathrm{~S}\right] \mathrm{GTP} \gamma \mathrm{S}$ binding in morphine-dependent mice. Drug Alcohol Depend 50: 241-249.

Rowen DW, Embrey JP, Moore CH, Welch SP (1998). Antisense oligodeoxynucleotides to Kappal receptor enhance $\Delta^{9}$-THCinduced antinociceptive tolerance. Pharmacol Biochem Behav 59: 399-404.

Rubino T, Tizzoni L, Vigano D, Massi P, Parolaro D (1997). Modulation of rat brain cannabinoid receptors after chronic morphine treatment. Neuroreport 8: 3219-3223.

Sala M, Braida D, Leone MP, Calcaterra P, Frattola D, Gori E (1994). Chronic morphine affects working memory during treatment and withdrawal in rats: possible residual long-term impairment. Behav Pharmacol 5: 570-580.

Schmid PC, Krebsbach RJ, Perry SR, Dettmer TM, Maasson JL, Schmid HHO (1995). Occurrence and postmortem generation of anandamide and other long-chain $\mathrm{N}$-acylethanol-amines in mammalian brain. FEBS Lett 375: 117-120.

Shapira M, Gafni M, Sarne Y (1998). Independence of, interactions between, cannabinoid and opioid signal transduction pathways in N18TG2 cells. Brain Res 806: 26-35.

Sim SJ, Hampson RE, Deadwyler SA, Childers SR (1996). Effects of chronic treatment with $\Delta^{9}$-tetrahydrocannabinol on cannabi- 
noid-stimulated $\left[{ }^{35} \mathrm{~S}\right] \mathrm{GTP} \gamma \mathrm{S}$ autoradiography in rat brain. $J$ Neurosci 16: 2684-2692.

Stella N, Schweitzer P, Piomelli D (1997). A second endogenous cannabinoid that modulate long-term potentiation. Nature 388: 773-778.

Thorat SN, Bhargava HN (1994). Evidence for a bidirectional cross-tolerance between morphine and $\Delta^{9}$-tetrahydrocannabinol in mice. Eur J Pharmacol 260: 5-13.

Valverde O, Noble F, Beslot F, Dauge V, Fournie-Zaluski MC, Roques BP (2001). Delta9-tetrahydrocannabinol releases and facilitates the effects of endogenous enklephalins: reduction in morphine withdrawal syndrome without change in rewarding effect. Eur J Neurosci 13: 1816-1824.
Welch S, Eads M (1999). Synergistic interactions of endogenous opioids and cannabinoid systems. Brain Res 848: 183-190.

Wenger T, Ledent C, Csernus V, Gerendai I (2001). The central cannabinoid receptor inactivation suppresses endocrine reproductive functions. Biochem Biophys Res Comm 284: 363-368.

Wolf DH, Numan S, Nestler EJ, Russel DS (1999). Regulation of phospholipase Cgamma in the mesolimbic dopamine system by chronic morphine administration. $J$ Neurochem 73: $1520-1528$.

Yamaguchi T, Hagiwara Y, Tanaka H, Sugiura T, Waku K, Shoyama Y et al (2001). Endogenous cannabinoid, 2-arachidonoylglycerol, attenuates naloxone-precipitated withdrawal signs in morphine-dependent mice. Brain Res 909: 121-126. 